had the typical facial appearance with a small upturned nose, long philtrum, a rather large mouth with a thin upper lip, low set ears, and epicanthic folds. Mother had smoked between 20 and 40 cigarettes a day during pregnancy but gave no definite history of taking alcohol. When I discussed this with her she said, with conviction that she did not like alcohol and she stuck to soft drinks. She added, 'but it's the child's father who drinks, in fact the only time he visited the child he was drunk'. She said it was a family joke that they thought that the child's red nose was due to her father being an alcoholic.

Perhaps if we also looked into the alcoholic intake of the sperm we might have better understanding of the syndrome. I understand from my senior house officer that Carthage recognised that it was a bad thing to take wine on the nuptial night. ${ }^{2}$

EILEEN E HILL East Birmingham Hospital, Birmingham B9 5ST

\section{Professor Smithells and Dr Smith comment:}

Dr Hill is not the first to report the features of fetal alcohol syndrome in the offspring of a mother who denies taking alcohol. Hanson, Streissguth, and $\mathrm{Smith}^{3}$ identified 11 newborns who were 'abnormal with features of FAS'. Little or no alcohol had been consumed by two of the mothers in the month before pregnancy and by four during the first five months of pregnancy. It is therefore at least possible that there are phenocopies of fetal alcohol syndrome not associated with alcohol. Hence our caution in subscribing to the notion of a specific syndrome.

Histories of alcohol intake are notoriously inaccurate if routine questions are used ${ }^{4}$ and we must all judge the reliability of any information given to us by parents. Even after fairly intensive questioning, about half the mothers of thalidomide damaged children denied having taken the drug, although the analogy with alcohol is not particularly close.

The role of the drunken father is even more difficult to study. In Carthage and in Greece the wedding reception was indeed 'dry', 5 and the lameness of the god Vulcan was attributed to his having been sired by Jupiter when in a drunken stupor. ${ }^{6}$ The old testament was content to advise against alcohol during pregnancy (Judges 13:7). We have no great difficulty envisaging an inebriated sperm weaving its way up to the fallopian tube and, with one last supreme lurch, penetrating a chaste and unsuspecting egg. We have more difficulty believing that the dose of ethanol thereby delivered could have a profound influence on fetal growth for nine months and on embryological events still weeks away.

But we are men, and Dr Hill is not!

\footnotetext{
References

1 Smithells RW, Smith IJ. Alcohol and the fetus. Arch Dis Child 1984;59:1113-4

2 Jones KL, Smith DW. Recognition of the fetal alcohol syndrome in early infancy. Lancet 1973;ii:999-1001.

${ }^{3}$ Hanson JW, Streissguth AP, Smith DW. Effects of moderate
}

alcohol consumption during pregnancy on fetal growth and morphogenesis. J Pediatr 1978;92:457-60.

${ }^{4}$ Barrison IG, Viola L, Murray-Lyon IM. Do housemen take an adequate drinking history. Br Med $J$ 1980;ii:1040.

5 Haggard HW, Jellinek EM. Alcohol explored. Doubleday Doran, New York. 1942.

${ }^{6}$ Rasmussen BB, Christensen N. Alkohol og fosterskader. Ugeskrift for Laeger (Copenhagen). 1978;140:282-4.

\section{High and conventional ventilation rates in the newborn}

Sir,

Dr Field and colleagues' interesting study ${ }^{1}$ on the effect of mechanical ventilation at rates of less than 50 and of $100 /$ minute on oxygenation and spontaneous respiration prompts three questions.

(1) What flow rates were used during the studies and were they altered in the transition from slower to more rapid rates in order to maintain the other ventilator settings constant?

(2) How can the authors exclude the possibility that the changes in oxygenation seen during transition from slow to fast rates were not a reflection of changes in mean airway pressure? For instance if flow was increased at fast rates, a consequent increase in mean airway pressure could account for all or part of the increased oxygenation documented in six infants.

(3) How many instances have the authors documented of the pattern of reflex expiratory effort against ventilator inflation which they cited ${ }^{2}$ and can they confirm that such babies develop pneumothoraces?

\section{W TaRnow-Mordi and A Wilkinson John Radcliffe Hospital, Oxford OX3 9DG}

\section{Dr Field and Professor Milner comment:}

We thank Drs Tarnow-Mordi and Wilkinson for their comments and, in answer to the points they have raised, we are able to add the following information;

(1) Ventilator flow rates were adjusted at the start of each study to compensate for the loss of bias flow through the pneumotachograph, and then remained constant for the duration of the investigation. They were approximately 6 litres/minute.

(2) We have looked formally at the effect of fast ventilator rates on mean airway pressure and found that the Draeger Babylog ventilator produces no significant variation in mean airways pressure when used over the range of ventilator rates employed in this study. ${ }^{3}$ We confirmed this finding in the babies reported in this study.

Some workers feel that the use of fast ventilator rates leads to an inadvertent positive end expiratory pressure within the lungs which affects gaseous exchange. Evidence in support of this phenomenon has been provided mainly by in vitro ${ }^{4}$ or animal studies. ${ }^{5}$ All our infants were in the acute phase of idiopathic respiratory distress syndrome and 